\title{
Capstone Design in Electrical and Computer Engineering Delivery and Assessment of ABET Criterion 3
}

\author{
James A. Reising \\ University of Evansville
}

\section{Introduction}

Several changes have been made to the Senior Design Project Course Sequence at the University of Evansville as previously described in "Senior Design Project Course Sequence, Electrical and Computer Engineering" to provide students with additional exposure to the non-technical aspects of engineering and to enable assessment of the outcomes of ABET Criterion $3^{2}$, listed below for easier reference in what follows:

(a) an ability to apply knowledge of mathematics, science, and engineering

(b) an ability to design and conduct experiments, as well as to analyze and interpret data

(c) an ability to design a system, component, or process to meet desired needs

(d) an ability to function on multi-disciplinary teams

(e) an ability to identify, formulate, and solve engineering problems

(f) an understanding of professional and ethical responsibility

(g) an ability to communicate effectively

(h) the broad education necessary to understand the impact of engineering solutions in a global and societal context

(i) a recognition of the need for, and an ability to engage in life-long learning

(j) a knowledge of contemporary issues

(k) an ability to use the techniques, skills, and modern engineering tools necessary for engineering practice.

The basic structure of the course sequence is the same as described in the earlier paper, consisting of three courses, usually taken in three consecutive semesters, starting in the spring of the junior year:
EE 494
Senior Project Seminar
( 0 credits)
EE 495
Senior Project Phase I
(3 credits)
EE 497
Senior Project Phase II
(3 credits)

The following table shows the typical amount of time spent in each unit in the courses.

Details of the courses and the changes that have been made (in italics) in the last seven years are covered in the later sections. 


\begin{tabular}{|l|l|}
\hline EE 494 & (one 50-minute session per week) \\
\hline & 1 st week - Introduction \\
\hline & 9 weeks - Project Sponsor Presentations \\
\hline & 2 weeks - Project Selection and Mini-proposal Preparation \\
\hline & 3 weeks - Class Presentations \\
\hline EE 495 & (two 75-minute sessions per week) \\
\hline & 4 weeks - Professional Ethics \\
\hline & 1 week - Practice Presentation of Problem \\
\hline EE 497 & \begin{tabular}{l} 
(one nominal 50-minute session per week) \\
\hline
\end{tabular} \\
\hline & \begin{tabular}{l} 
Last week - Completion of Design and Periodic Status Reports \\
\hline
\end{tabular} \\
\hline
\end{tabular}

\section{EE 494 Senior Project Seminar}

The senior project seminar meets for one fifty-minute session in each of the fifteen weeks of a typical semester. The first class meeting consists of an introduction to the senior project sequence and the nature of the design process. The iterative nature of the design process and the need to consider alternative approaches to the solution of a problem are two of the topics discussed in the first session.

The next nine class sessions provide an opportunity for potential project sponsors to present their ideas to the class. In recent years many of the project sponsors have been faculty members serving as industrial sponsors for projects in which they have a particular interest or projects related to consulting work or course development. Students sometimes generate their own project ideas subject to faculty approval. Two current projects originated by students are a wireless Mp3 controller and a remote starter system for vehicles with features not available in commercial models. Many projects involve a single student; some require teams of two students. This year a sponsor from a local business intends to provide one or more multi-disciplinary team projects requiring the skills from more than one engineering discipline for successful completion. Since the capstone design course structure at the University of Evansville is somewhat different in mechanical and civil engineering than in electrical and computer engineering, the departments involved have completed the design of a course structure more suitable for such projects.

During the following two weeks students are tasked with selecting a project, gathering data, conducting a literature search, and preparing a one or two-page "mini-proposal" following the outline below:

I. Statement of Need (The client requirements)

a. What is the problem?

b. What is its origin?

c. Why is its solution important?

II. Work Done to Date by Others (if any) 
(Give a brief summary of major work efforts including their degree of success and/or failure and reasons for failure. Use this section to highlight the basis for expecting this work to be successful.)

\section{Statement of Proposed Work}
a. Objectives
b. Technical description of work to be done (including specifications)
c. Approach to solving problem
d. Examples and illustrations of why you think your approach will work
e. Equipment and facilities needed
f. Explanation of how the important acceptance criteria of the RFP will be satisfied

IV. Schedule and Milestone Events

(Select well-defined events throughout the program that can be used to measure progress towards objectives.)

V. Cost and Manpower Requirements
a. Equipment costs and types
b. Travel Costs
c. Number of man-hours required
d. Distinguish between one-time development costs and the recurring costs (if any).

At this stage students have made an initial attempt to identify the problem and formulate its solution (Criterion 3e). During the next course in the sequence they will be required to develop specifications for the finished product and a plan for testing the prototype.

The remaining three class sessions are devoted to brief oral presentations by the students, typically three to five minutes long, in which they describe the project they have chosen and their approach to solving it (Criterion 3g). The instructor can at this time determine if the client requirements presented by the students are appropriate to the projects as presented by the sponsors.

Each student is also required to select a faculty project advisor to serve as a technical consultant for the project chosen. The project faculty advisors play a significant role in the remaining two courses in the sequence.

Changes made in this first course of the sequence are relatively minor. The distinction between the requirements of the client and the formulation of the engineering specifications for the finished product has been emphasized to specifically address criteria $3 c$ and $3 e$. 


\section{EE 495 Senior Project Phase I}

This second course in the senior design sequence combines a study of professional ethics, practice in effective communication, and engineering design. The course meets for two seventyfive minute sessions in each of the fourteen weeks in a typical semester.

The first four weeks of the semester are devoted to professional ethics (Criterion 3f). Students participate in discussion of questions from the ethics section of a custom book ordered through the McGraw-Hill Primis system containing selections from Ethics in Engineering by MartinShinzinger. Groups of students prepare and present to the class their answers to questions posed in the text on such topics as loyalty, both of employee to employer and vice versa, conflicts of interest, and confidentiality. The student groups also submit written copies of their answers. Additional questions are assigned from among those presented at The Online Ethics Center for Engineering and Science at CASE Western University ${ }^{3}$. One example case from the Online Ethics Center involved the use of technical information and data contained in one engineer's proposal by another engineer. The example is based on a case ruled on by the NSPE Board of Ethical Review. A recent newspaper article ${ }^{4}$ concerning the Justice Department investigation of charges that Boeing Co. obtained Lockheed Martin Corp.'s proprietary documents and the misuse of proprietary information was the basis of another class discussion.

The significant change to this part of the course was the requirement that students submit their answers to discussion questions in writing. These papers are then used in the course assessment described later. The use of cases from the Online Ethics Center represents a change from the past in providing an additional source of material, but does not change the structure of the course. The students are reminded that criterion $3 f$ is an important aspect of the discipline. The use of the recent newspaper article involving prominent firms helped to emphasize this point and to illustrate its relationship to criterion $3 j$.

The final assignment during this part of the course requires students, in groups of three or four, to write their own code of ethics for engineers or engineering students after study of codes of ethics of ABET, NSPE, IEEE, and ACM. These papers, too, are collected and used for course assessment.

The remaining ten weeks of the semester are devoted to practicing and improving students' communication skills (Criterion 3g) and to developing a concept design for their projects. In the course of developing a proposal, students analyze the client requirements and, using their knowledge of engineering and related fields, formulate measurable specifications for a prototype. They are required to show in the proposal that a prototype meeting the specifications will, in fact, satisfy the client requirements. The proposal must also contain a section detailing a test plan for collecting the data necessary to determine that the prototype meets the specifications (Criteria 3a, $3 \mathrm{~b}, 3 \mathrm{c}, 3 \mathrm{e}$, and $3 \mathrm{k}$ ).

Changes made in this part of the course include requiring a detailed test plan, an itemization of client requirements, a list of specifications developed from the client requirements, and validation of the specifications. The proposal outline given to the students as a guide was 
modified to emphasize these changes, providing specific exposure to criteria $3 b$ and $3 c$. The written proposals submitted by the students provide data for course assessment.

Since EE 495 serves not only as part of the capstone design experience in the engineering program but also satisfies the senior seminar general education requirement, the importance of effective communication (Criterion $3 \mathrm{~g}$ ) is emphasized. At approximate two-week intervals, students submit draft copies of the introduction and technical approach, the technical plan and management plan, and the entire proposal to the instructor and to the faculty project advisor. The instructor grades and returns the drafts with comments and suggestions for revision. The instructor holds individual conferences with students after reading the draft copy of the entire proposal. The finished proposal is then due at the end of the course.

There has been no significant change in this requirement beyond that mentioned earlier. The emphasis on writing and revising the proposal, although directly addressing criterion $3 g$, does not represent a change.

To practice their oral communication skills, students give three presentations to the class. The instructor records each student's presentations on a separate cassette and requires the students to review their own presentations and submit their own evaluations in writing. In addition, each member of the audience anonymously fills out an evaluation form which is given to the presenter as aid to modifying future presentations. The first presentations start during the fifth week of the semester. This first presentation is primarily a statement of the problem and provides early experience in making a presentation to the class. The second presentations begin during the tenth week of the semester and serve as practice for the presentation of the entire proposal.

In the past, the videotapes were given to the students; the videotapes are now kept by the instructor for possible use in course assessment.

The course grade is determined by averaging the grade assigned by the instructor, based on all class activities, with the grade assigned by the project advisor, based on the technical quality of the proposal.

Copies of student proposals were sent to a group of volunteers from industry for their comments for the first time this year. No responses had been received at the time of this writing, however.

\section{EE 497 Senior Project Phase II}

Students complete the design, construction, and testing of their projects in the final semester. Status reports are required at approximate one-month intervals. Near the end of the semester, students give presentations and demonstrate their finished prototypes to an audience including a panel of judges, faculty members, guests, and interested students. As part of their presentations, students prepare posters illustrating their designs for display in the lobby of the building. The final presentations are held on one day near the end of the semester. The judges are volunteers from local industry. 
The judges complete a scorecard for each presentation, rating each of the following aspects on a scale of zero to ten (ten is best) or as not applicable:

1. Demonstrated ability to formulate problems and identify creative solutions

2. Demonstrated ability to complete an "open-ended" design from specifications

3. Demonstrated ability to design an experiment

4. Demonstrated ability to take measurements

5. Effectiveness of audio/visual presentation

6. Quality of oral presentation

7. $\quad$ Rationale for design choice

(Consideration of alternative designs, technical risks, economic and schedule factors, other sponsor constraints.)

8. $\quad$ Project execution quality

(Planning, teamwork, workmanship, on-schedule?)

9. Real value to industrial sponsor of the work done

10. $\quad$ Results vs. Objectives

(Comparison of project results with project goals for performance, cost, etc.)

Following the presentations, the faculty meets with the judges as a group to obtain their overall impression of the projects as a whole and to invite suggestions for improving the capstone design experience. Judges also suggest candidates for awards. Course coordinators prepare summaries of the judges' scorecard ratings and a report of the meeting with the judges for use in later course assessment.

Grades for the course are determined by the faculty as a group, based on the students' final reports, presentations, posters, and input from the project faculty advisors.

The poster presentations provide additional support of criterion $3 g$. There were two other changes made in the course to aid in the assessment process. Grades for the course are now determined by the faculty as a group, whereas previously course grades were assigned by the faculty project advisors. The coordinator's written report of the meeting with the judges constitutes the other change.

\section{Assessment}

There are two mechanisms by which the faculty assesses the capstone design experience. An "assessment day" occurs at the end of each semester. Faculty groups review major course sequences and assess individual courses in the curriculum. Different course sequences and individual courses are selected on a rotating basis. The three courses in the senior project sequence are reviewed as a course sequence using syllabi and reports of the meetings with the judges. EE 495 is one of the courses assessed individually. Portfolios containing all the written work submitted by five "typical" students are examined by a group of faculty to determine if the relevant outcomes in ABET Criterion 3 are adequately demonstrated in the work in the portfolios. 
Most of the changes made in the course sequence have been made to facilitate assessment of the relevant outcomes in ABET Criterion 3 by providing additional documentation of student work, although a few, as outlined above, have the added advantage of specifically addressing particular outcomes.

\section{Summary}

Changes in the senior project course sequence have made demonstration of ABET-required outcomes easier. The student portfolios used for individual course assessment now contain written documentation in support of specific criterion 3 outcomes. Since a few of the changes served to increase student awareness of various criterion 3 outcomes, the stated objectives have been improved. Perhaps the emphasis on a detailed test plan represents the greatest substantive improvement in the overall design process description.

Since no major structural changes in the course sequence were necessary, the effort required to effect the changes was relatively small.

The department faculty suggested most of the changes outlined above during previous course assessment activities. The faculty has since reviewed all the changes, the consensus being that all have been beneficial.

The fact that a few relatively small changes in the existing capstone design sequence have made assessment of the criterion 3 outcomes addressed by the courses easier suggests that a similar strategy could be of use to other institutions.

\section{Examples of recent projects}

Wireless Mp3 Controller

8-Computer Cluster Running Open MOSIX Investigating Genetic Algorithm

Remote Control Multifunction Power Outlet

Car Audio Power Amplifier (Class D)

Fire-Fighting Robot

Electronic Dartboard

Remote Temperature-Sensing Device (utilizing RF link to PC)

Web-based Appliance Manager

Fireworks Display Controller (Microcontroller w/RF link to firing unit)

Linux device driver for Keithley KPCI-3108 A/D and D/A

Artificial Daylight Simulator

End-User Client for Creating Indexes for Internet Search Engine.

Surface Plasmon Experiment Equipment

Infrared Identification and Tracking Device

Electronic Mine Hoist Safety Monitor

Styrofoam Panel Cutting Machine

Ping-Pong-playing machine (IEEE contest entry)

Chess-playing robot 


\section{The University of Evansville and EE/CS Department}

The University of Evansville is a fully-accredited, private, liberal arts and sciences based university affiliated with the United Methodist Church, proudly celebrating a history of 150 years. Full-time undergraduate enrollment is approximately 2,200 students. The department of Electrical Engineering and Computer Science offers Bachelor of Science degrees in Electrical Engineering, Computer Engineering, and Computer Science. The department also supports an interdisciplinary degree in Information Technology. There are currently eleven full-time faculty members in the department and 115 students working toward degrees in Electrical Engineering, Computer Engineering, and Computer Science, with 35 enrolled in the Computer Engineering program and 42 enrolled in the Electrical Engineering program. About $20 \%$ of electrical engineering and computer engineering graduates have gone on to graduate school in recent years.

\section{Bibliography}

1. Reising, James A. "Senior Design Project Course Sequence, Electrical and Computer Engineering." ASEE Annual Conference. Milwaukee, WI. June 1997

2. ABET, Inc. Criteria for Accrediting Engineering Programs. 2003.<http://www.abet.org $>$

3. The Online Ethics Center for Engineering and Science at CASE Western University < http://onlineethics.org/>

4. Lunsford, J. Lynn and Squeo, Anne Marie. "Boeing CEO Condit Resigns In Shake-Up at Aerospace Titan.” The Wall Street Journal. 2 December 2003.

JAMES A. REISING is an Associate Professor of Electrical Engineering at the University of Evansville, Evansville, Indiana, where he has taught since 1980. Prior to that time he was employed by Eagle-Picher Industries at the Miami Research Laboratories and the Electro-Optic Materials Department. He is a senior member of IEEE and has been senior project coordinator for electrical and computer engineering at the University of Evansville since 1982. 